\title{
Correction to: Fluid Biomarkers for Monitoring Structural Changes in Polyneuropathies: Their Use in Clinical Practice and Trials
}

\author{
Luuk Wieske $^{1} \cdot$ Duncan Smyth ${ }^{2,3} \cdot$ Michael P. Lunn $^{2,3} \cdot$ Filip Eftimov $^{1} \cdot$ Charlotte E. Teunissen $^{4}$ \\ Published online: 2 December 2021 \\ (c) The American Society for Experimental NeuroTherapeutics, Inc. 2021
}

Correction to: Neurotherapeutics (2021)

https://doi.org/10.1007/s13311-021-01136-0

This correction is for the additional edits to the original article.

The original has been corrected.

Publisher's Note Springer Nature remains neutral with regard to jurisdictional claims in published maps and institutional affiliations.

The original article can be found online at https://doi.org/10.1007/ s13311-021-01136-0.

Charlotte E. Teunissen

c.teunissen@amsterdamumc.nl

1 Department of Neurology and Neurophysiology, Amsterdam Neuroscience, Amsterdam UMC, Location AMC, Amsterdam, the Netherlands

2 Centre for Neuromuscular Disease, National Hospital for Neurology and Neurosurgery, London, UK

3 UCL Queen Square Institute of Neurology, London, UK

4 Neurochemistry Lab, Department of Clinical Chemistry, Amsterdam Neuroscience, Amsterdam UMC, Vrije Universiteit, Amsterdam, the Netherlands 